p-ISSN : 2686-1437

e-ISSN : 2686-0201

http://ejournal.ukrida.ac.id/ojs/index.php/Meditek/index

\title{
Gambaran Risiko Kejadian Carpal Tunnel Syndrome pada Karyawan Administrasi Universitas Kristen Krida Wacana
}

\author{
Suparto $^{1}$, Vanessa Malise Lisandra ${ }^{2}$, Irvan Tanpomas ${ }^{1}$, Citra Rencana Perangin-angin ${ }^{1}$ \\ ${ }^{1}$ Departemen Anestesiologi Fakultas Kedokteran dan Ilmu Kesehatan \\ Universitas Kristen Krida Wacana, Jakarta, Indonesia \\ ${ }^{2}$ Fakultas Kedokteran dan Ilmu Kesehatan Universitas Kristen Krida Wacana, Jakarta, Indonesia. \\ Alamat Korespondensi: suparto@ukrida.ac.id
}

\begin{abstract}
Abstrak
Carpal Tunnel Syndrome (CTS) adalah gangguan saraf pada ekstremitas atas di mana nervus medianus terhimpit. Gangguan ini disebabkan oleh berbagai faktor yang mengakibatkan penyempitan terowongan karpal. Penyebab paling umum adalah pekerjaan dengan gerakan mengetik atau fleksi dan ekstensi pergelangan tangan berulang. Penelitian ini dilakukan untuk mengetahui gambaran kejadian CTS pada karyawan administrasi yang menggunakan komputer setiap harinya berdasarkan keluhan utama, usia, jenis kelamin, lama mengetik, masa kerja, posisi pergelangan tangan dan tes phalen. Sampel diperoleh dengan cara purposive sampling. Data penelitian dikumpulkan melalui kuesioner serta tes phalen dan diolah menggunakan program SPSS 23. Hasil penelitian dari 29 responden didapatkan gambaran risiko CTS dengan rentang usia 40-60 tahun sebanyak 11 responden (37,9\%) berisiko CTS, 16 responden $(55,2 \%)$ positif CTS. Karyawan dengan lama bekerja lebih dari 4 jam per hari dan berisiko CTS sebanyak 18 responden $(62,1 \%)$ dan karyawan dengan masa kerja lebih dari 4 tahun dan berisiko CTS sebanyak 23 responden $(79,3 \%)$. Sebanyak 16 responden $(55,2 \%)$ dengan posisi pergelangan tangan janggal berisiko mengalami CTS. Studi menyimpulkan bahwa angka kejadian CTS pada karyawan administrasi meningkat seiring dengan bertambahnya usia, lama bekerja dan posisi pergelangan tangan yang janggal pada saat bekerja. Karena itu, edukasi kepada karyawan administrasi mengenai faktor yang dapat menyebabkan CTS harus dilakukan.
\end{abstract}

Kata kunci: carpal tunnel syndrome, karyawan administrasi

\section{Description of Carpal Tunnel Syndrome Risk in University Administrative Employees}

\begin{abstract}
Carpal Tunnel Syndrome (CTS) is a neurological disorder on upper extremities in which the medianus nerve is impinged. Carpal tunnel entrapment can be caused by multiple causes. One of the most common cause is job-related activities of repeated flexion and extension of wrist such as in typing activity. This study aimed to describe the incidence of CTS in university administrative employees. This was a crosssectional study conducted at Krida Wacana University in 2019. Twenty-nine respondents were included in the study by a purposive sampling. Subjects filled out questionnaires describing troubling symptoms, age, gender, typing duration per day, work period, wrist position, and Phalen's test to assess CTS incidence. Data were analysed with SPSS 23 software. Incidence risk for CTS was found in respondents from various age groups (40-60 years old), with 11 (37.9\%) respondents were CTS-risk, and 16 respondents were CTS-positive. Eighteen respondents with typing duration of > 4 hours/day was found to be at risk for CTS. Of respondents group with odd wrist position, $16(55.2 \%)$ of them were at risk to suffer CTS. The study concludes that the incidence of CTS in administrative employee increases with advancing age, working duration, and awkward hand position while working. Thus, education is required for the administrative employees about factors causing CTS risks.
\end{abstract}

Keywords: administration staff, carpal tunnel syndrom

How to Cite this article :

Suparto S, Lisandra V, Tanpomas I, Perangin-angin C. Gambaran Risiko Kejadian Carpal Tunnel Syndrome pada Karyawan Administrasi Universitas Kristen Krida Wacana. JKdoktMeditek;26(2):71-76. Available from: http://ejournal.ukrida.ac.id/ojs/index.php/Meditek/article/view/1845. DOI: $\underline{\text { https://doi.org/10.36452/jkdoktmeditek.v26i2.1845 }}$ 


\section{Pendahuluan}

Carpal Tunnel Syndrome (CTS) adalah gangguan saraf pada ekstremitas atas di mana nervus medianus terhimpit. ${ }^{1,2}$ Nervus medianus terletak di terowongan karpal pada pergelangan tangan dengan lebar sekitar 1 inci. Terowongan ini terbentuk atas tulang-tulang karpal. ${ }^{3}$ Fungsi dari terowongan tersebut adalah melindungi nervus medianus serta tendon fleksor yang menggerakkan tangan dan ibu jari. Ketika terjadi penyempitan, baik disebabkan oleh edema ataupun kelainan anatomi tulang-tulang karpal, maka nervus medianus dan tendon fleksor akan tertekan sehingga menimbulkan nyeri, baal, rasa terbakar pada jari-jari yang dipersarafi oleh nervus medianus. ${ }^{1,2,3}$

Gangguan ini disebabkan oleh berbagai faktor yang mengakibatkan penyempitan terowongan karpal. Beberapa faktor tersebut adalah trauma atau luka pada pergelangan tangan yang menyebabkan pembengkakan seperti fraktur, peningkatan aktivitas kelenjar pituitari, dan rheumatoid arthritis. ${ }^{1,3,4}$ Masalah mekanik pada pergelangan tangan seperti pada beberapa pekerjaan, retensi cairan saat hamil atau menopause, adanya kista atau tumor juga dapat menjadi faktor risiko lain. Namun penyebab paling umum adalah pekerjaan dengan gerakan mengetuk atau fleksi dan ekstensi pergelangan tangan berulang. ${ }^{5,6}$

Berdasarkan Washington State worker's compensation record terdapat $0,8-14,8$ per 1000 pekerja per tahunnya yang menderita kasus CTS dan persentase setiap pekerjaan bervariasi. Selain itu, terdapat penelitian lainnya yang mengobservasi 432 pekerja industri dan pekerjaan yang berhubungan dengan agama memiliki prevalensi kasus $12,4 \%$ dari 1000 orang per tahunnya dengan menggunakan elektrodiagnostik. ${ }^{3}$ Pada tahun 2003 sampai 2005, di Indonesia terdapat peningkatan kasus Carpal Tunnel Sydrome pada karyawan yang menggunakan komputer dalam frekuensi sering dan dalam jangka waktu yang lama yaitu dari 76 kasus menjadi 112 kasus. $^{4}$

Universitas memiliki beberapa bagian untuk menyelenggarakan kegiatan sehari-hari. Salah satu bagian yang bekerja dalam suratmenyurat adalah bagian administrasi. Bagian administrasi dalam jenjang perkuliahan dilaksanakan oleh dua pihak, Unit Administrasi Akademik dan Tata Usaha. Kedua unit ini berfungsi untuk merencanakan, mengatur, melaksanakan, dan mengawasi hal-hal dalam bidang akademik yang bersifat teknis dan administratif. Dalam kegiatan sehari-harinya, karyawan kedua unit ini tidak lepas dari pemakaian teknologi komputer dalam jangka waktu yang lama. Hal ini cenderung membuat tangan dalam posisi janggal yang menjadi salah satu faktor risiko munculnya CTS.

Penelitian ini bertujuan untuk mengetahui gambaran risiko kejadian CTS pada karyawan administrasi yang meliputi keluhan subjektif, usia, jenis kelamin, lama mengetik, masa kerja, posisi pergelangan tangan, dan tes phalen.

\section{Metodologi}

Penelitian ini menggunakan desain penelitian deskriptif dengan pendekatan crosssectional. Cara untuk memperoleh sampel dengan menggunakan metode purposive sampling. Perkiraan besar sampel minimal yang dihitung dengan rumus Lemeshow didapatkan sebanyak 29 responden. Kriteria inklusi dari penelitian ini adalah karyawan administrasi di Universitas Kristen Krida Wacana tahun 2019 yang berusia 40-60 tahun, menggunakan komputer dalam pekerjaan sehari-harinya dan bersedia menjadi sampel penelitian. Kriteria eksklusi adalah karyawan yang memiliki penyakit reumatik dan atau pernah mengalami trauma pada regio lengan bawah.

Penelitian ini sudah mendapatkan surat keterangan lolos kaji etik nomor pengajuan: 806/SLKE-IM/UKKW/FKIK/KE/VI/2019.

Data diolah menggunakan program SPSS 23 (Statistical Program for Social Science). Analisis data dalam penelitian ini merupakan analisis data univariat untuk melihat gambaran data distribusi kejadian CTS pada karyawan administrasi berdasarkan parameter yang meliputi keluhan subjektif, usia, jenis kelamin, lama mengetik, masa kerja, posisi pergelangan tangan, dan tes phalen.

\section{Hasil dan Pembahasan}

Hasil penelitian dan pembahasan disajikan dalam bentuk tabel-tabel gambaran demografis dan karakteristik responden terhadap gambaran risiko CTS.

Tabel 1 menunjukkan bahwa sebagian besar responden berusia 40-45 tahun, yaitu sebanyak 19 orang $(65,6 \%)$. Kelompok usia 
yang paling sedikit adalah 51-55 tahun yaitu 1 orang $(3,4 \%)$.

Tabel 1. Gambaran usia

\begin{tabular}{ccc}
\hline & Frekuensi & Persentase \\
\hline 40-45 tahun & 19 & 65,5 \\
46-50 tahun & 7 & 24,1 \\
$\mathbf{5 1 - 5 5}$ tahun & 1 & 3,4 \\
$\mathbf{5 6 - 6 0}$ tahun & 2 & 6,9 \\
Total & 29 & 100 \\
\hline
\end{tabular}

Tabel 2 menunjukkan sebagian besar responden memiliki jenis kelamin laki-laki dengan jumlah 16 orang $(55,2 \%)$ dan sebagian lagi merupakan perempuan sebanyak 13 orang $(44,8 \%)$.

Tabel 2. Gambaran Jenis Kelamin

\begin{tabular}{ccc}
\hline & Frekuensi & Persentase \\
\hline Laki-laki & 16 & 55,2 \\
Perempuan & 13 & 44,8 \\
\hline Total & 29 & 100 \\
\hline
\end{tabular}

Tabel 3 menunjukkan bahwa usia responden yang mengalami CTS bervariasi dari usia 40-60 tahun, di mana dari penelitian ini menunjukkan bahwa hampir seluruh kategori usia adalah berisiko CTS. Penelitian Rovita (2012) mengungkapkan usia 30-60 tahun merupakan usia rawan mengalami CTS. Jangka usia tersebut dipersempit lagi melalui penelitian lanjutan oleh Firsan Ilyas (2015) menjadi usia 42 tahun ke atas. Paparan alat kerja dengan tangan serta waktu kerja yang lama mengurangi kemampuan elastisitas tulang, otot, maupun saraf sehingga kejadian CTS baru dialami di usia lanjut. ${ }^{5-8}$

Tabel 3. Gambaran Usia Terhadap Resiko Kejadian CTS

\begin{tabular}{ccc}
\hline & \multicolumn{2}{c}{ Gambaran CTS } \\
\cline { 2 - 3 } & Tidak CTS & $\begin{array}{c}\text { Berisiko } \\
\text { CTS }\end{array}$ \\
\hline $\mathbf{4 0 - 4 5}$ tahun & $2(6,9 \%)$ & $17(58,6 \%)$ \\
$\mathbf{4 6 - 5 0}$ tahun & $0(0,0 \%)$ & $7(24,1 \%)$ \\
$\mathbf{5 1 - 5 5}$ tahun & $0(0,0 \%)$ & $1(3,4 \%)$ \\
$\mathbf{5 6 - 6 0}$ tahun & $0(0,0 \%)$ & $2(6,9 \%)$ \\
\hline Total & $2(6,9 \%)$ & $27(93,1 \%)$ \\
\hline
\end{tabular}

Tabel 4 menunjukkan perbandingan antara jenis kelamin dengan kejadian risiko CTS didapatkan bahwa kedua jenis kelamin memiliki persentase besar berisiko mengidap CTS. Pada perempuan, berdasarkan penelitian Rovita, angka kejadian CTS lebih sering terjadi pada perempuan berusia antara 45 dan 54 di mana usia tersebut berhubungan dengan usia menopause. ${ }^{5,6,9,10}$

Tabel 4. Gambaran Jenis Kelamin terhadap Kejadian Resiko CTS

\begin{tabular}{ccc}
\hline & \multicolumn{2}{c}{ Gambaran CTS } \\
\cline { 2 - 3 } & Tidak CTS & Berisiko CTS \\
\hline Laki-laki & $1(3,4 \%)$ & $15(51,7 \%)$ \\
Perempuan & $1(3,4 \%)$ & $12(41,4 \%)$ \\
\hline Total & $2(6,9 \%)$ & $27(100 \%)$ \\
\hline
\end{tabular}

Tabel 5 menunjukkan bahwa semua responden yang bekerja kurang dari 4 jam per hari sebanyak 9 responden, berisiko mengalami CTS. Sementara pada karyawan yang bekerja 4 jam atau lebih per harinya sebanyak 18 responden $(62,1 \%)$ berisiko mengalami CTS. Total karyawan administrasi yang berisiko CTS adalah 27 responden dari 29 responden. Hasil ini sejalan dengan pernyataan dari Accident Compensation Coorporation di mana kecelakaan pekerja akan meningkat apabila pekerja bekerja lebih dari $20 \mathrm{jam} / \mathrm{minggu}$ atau 4 jam/hari (hari Sabtu dan Minggu tidak dihitung). ${ }^{7,11,12}$

Tabel 5. Gambaran Lama Mengetik terhadap Kejadian Risiko CTS

\begin{tabular}{ccc}
\hline & \multicolumn{2}{c}{ Gambaran CTS } \\
\cline { 2 - 3 } & Tidak CTS & $\begin{array}{c}\text { Berisiko } \\
\text { CTS }\end{array}$ \\
\hline $\begin{array}{c}\text { Kurang dari 4 jam/ } \\
\text { hari }\end{array}$ & $0(0,0 \%)$ & $9(31,0 \%)$ \\
4 jam atau lebih/ hari & $2(6,9 \%)$ & $18(62,1 \%)$ \\
\hline Total & $2(6,9 \%)$ & $27(93,1 \%)$ \\
\hline
\end{tabular}

Berdasarkan tabel 6, karyawan yang bekerja mengetik selama lebih dari 4 tahun adalah sebanyak 24 responden $(82,8 \%)$ dan 23 responden $(79,3 \%)$ di antaranya mengalami CTS. Karyawan yang bekerja di bawah 4 tahun sebanyak $5(17,2 \%)$ responden dan yang mengalami CTS adalah $4(13,8 \%)$ responden. Hasil ini sesuai dengan penelitian Bahrudin dkk. yang mengemukakan bahwa semakin lama masa kerja maka semakin tinggi angka kejadian CTS. ${ }^{8,9}$ Masa kerja menunjukkan lamanya 
paparan di tempat kerja. Dalam hal mengetik, maka pergelangan tangan dipaksa untuk fleksi dan ekstensi terus-menerus dan mengakibatkan peradangan pada pergelangan tangan sehingga saraf medianus di dalamnya terhimpit dan terjadi CTS..$^{10,13,14,15}$

Tabel 6. Gambaran Masa Kerja terhadap Kejadian Risiko CTS

\begin{tabular}{ccc}
\hline & \multicolumn{2}{c}{ Gambaran CTS } \\
\cline { 2 - 3 } & Tidak CTS & Berisiko CTS \\
\hline $\begin{array}{c}\text { Kurang dari 4 } \\
\text { tahun } \\
\text { 4 tahun atau } \\
\text { lebih }\end{array}$ & $1(3,4 \%)$ & $4(13,8 \%)$ \\
\hline Total & $1(3,4 \%)$ & $23(79,3 \%)$ \\
\hline
\end{tabular}

Pada tabel 7 terlihat bahwa jumlah responden yang memiliki posisi janggal saat memakai tetikus (tidak dalam posisi netral) berjumlah $17(58,6 \%)$ responden dan yang mengalami CTS adalah $16(55,2 \%)$ responden. Sementara pada karyawan dengan posisi netral berjumlah $12(41,4 \%)$ responden dengan yang berisiko CTS sebanyak 11 (37,9\%) responden. Hal ini sesuai dengan penelitian Ilyas yang menyatakan terdapat hubungan antara pergelangan tangan yang janggal dengan kejadian CTS. Begitu pula dengan penelitian Setiawan (2019) yang menyatakan adanya hubungan posisi pergelangan tangan dengan risiko kejadian CTS. ${ }^{11,16-18}$ Proses pemakaian tetikus dalam keseharian karyawan administrasi mengakibatkan tangan menggenggam tetikus terus-menerus dan menggerakkannya ke kanan dan kiri atau tidak lurus (netral). Dalam keadaan di luar netral/ janggal akan terjadi penekanan atau penegangan pada saraf di pergelangan tangan sehingga terjadi CTS. ${ }^{19,20}$ Hal ini disebabkan oleh banyaknya faktor lain pencetus CTS selain posisi pergelangan tangan yang janggal. Adapun 11 (37,9\%) responden yang berisiko mengalami CTS pada karyawan dengan posisi netral kemungkin disebabkan oleh banyaknya faktor pencetus CTS selain posisi tangan tersebut.
Tabel 7. Gambaran Posisi Pergelangan Tangan terhadap Risiko Kejadian CTS

\begin{tabular}{ccc}
\hline & \multicolumn{2}{c}{ Gambaran CTS } \\
\cline { 2 - 3 } & Tidak & Berisiko \\
& CTS & CTS \\
\hline Janggal & $1(3,4 \%)$ & $16(55,2 \%)$ \\
Tidak Janggal & $1(3,4 \%)$ & $11(37,9 \%)$ \\
\hline Total & $2(6,9 \%)$ & $27(93,1 \%)$ \\
\hline
\end{tabular}

Tabel 8 menunjukkan hasil dari kuesioner dan tes phalen yang telah dilakukan. Dari hasil tersebut, responden yang terkena CTS memiliki hasil kuesioner dan tes phalen yang positif. Apabila salah satu hasil negatif, maka responden dinilai berisiko terkena CTS. Sementara jika kedua hasil negatif maka dinyatakan bahwa responden tidak berisiko ataupun terkena CTS. Pada tabel 8 didapatkan bahwa sebanyak 16 responden $(55,2 \%)$ positif CTS dan 11 responden $(37,4 \%)$ berisiko mengalami CTS,. Adapun 2 responden $(6,9 \%)$ tidak mengalami CTS ataupun memiliki risiko terkena CTS.

Tabel 8. Gambaran Kejadian Risiko CTS

\begin{tabular}{cccc}
\hline Tes Phalen & Hasil Kuesioner & Frekuensi & Persentase \\
\hline CTS & Tidak CTS & 1 & 3,4 \\
& CTS & 16 & 55,2 \\
& Total & 17 & 58,6 \\
Tidak & Tidak CTS & 2 & 6,9 \\
CTS & & & \\
& CTS & 10 & 34,5 \\
& Total & 12 & 41,4 \\
Total & Tidak CTS & 2 & 6,9 \\
& Berisiko & 27 & 93,1 \\
& CTS & & \\
& Total & 29 & 100 \\
\hline
\end{tabular}

\section{Simpulan}

Berdasarkan hasil penelitian yang telah dilakukan, dapat disimpulkan bahwa gambaran risiko kejadian CTS pada karyawan administrasi UKRIDA sejumlah $11(37,4 \%)$ responden, $16(55,2 \%)$ responden positif CTS dan $2(6,9 \%)$ responden lainnya tidak terkena CTS ataupun memiliki risiko terkena CTS. Usia responden yang mengalami CTS bervariasi dari 40-60 tahun dan prevalensi antar jenis kelamin tidak jauh berbeda yaitu laki-laki 55,2\% dan perempuan $44,8 \%$. Sebagian besar karyawan yang bekerja minimal 4 jam per harinya dengan masa kerja dalam bidang administrasi lebih dari 
4 tahun memiliki risiko terkena CTS lebih tinggi dibandingkan dengan karyawan yang bekerja di bawah 4 jam per harinya dan bekerja kurang dari 4 tahun. Sebagian besar karyawan memiliki posisi pergelangan tangan yang janggal/ tidak netral ketika menggunakan tetikus dalam pekerjaannya. Sebagai saran dari hasil penelitian adalah agar universitas dapat melakukan edukasi kepada karyawan administrasi mengenai faktor-faktor yang dapat menyebabkan CTS. Serta penelitian berikutnya untuk melakukan observasi posisi janggal tangan dalam waktu yang cukup lama dan beberapa kali untuk memastikan bahwa gerakan yang diihat merupakan gerakan tersering.

\section{Daftar Pustaka}

1. Jennings C, Faust K. Carpal tunnel syndrome. Orthoinfo. 2016 [disitasi 6 April 2018]. Tersedia dari: https://orthoinfo.aaos.org/en/diseases-conditions/carpal-tunnel-syndrome/

2. Moore KL, Dalley AF, Agur AM. Clinically oriented anatomy. $8^{\text {th }}$ ed. Philadelphia: Wolters Kluwer, 2018.

3. Snell RS. Clinical anatomy. $4^{\text {th }}$ ed. Balimore: Lipincott, 2004.

4. Dale A, Harris-Adamson C, Rempel D, Gerr F, Hegmann K, Silverstein B, et al. Prevalence and incidence of carpal tunnel syndrome in US working populations: pooled analysis of six prospective studies. Scandinavian Journal of Work, Environment \& Health. 2013;39(5):495505.

5. Burke F. Primary care management of carpal tunnel syndrome. Postgraduate Medical Journal. 2003 [disitasi 6 April 2018];79(934):433-37. Tersedia dari:http://pmj.bmj.com/content/79/934/4 33

6. Lusianwati TD. Peran latihan tangan dalam pencegahan carpal tunnel syndrome pada wanita pekerja garmen. Jurnal ekologi kesehatan. 2018;11(2).

7. Fitriani RN. Faktor-faktor yang berhubungan dengan dugaan carpal tunnel syndrome (CTS) pada operator komputer bagian sekretariat di Inspektorat Jenderal Kementrian Pekerjaan Umum. Jakarta: Universitas Islam Negeri Syarif Hidayatullah, 2012.
8. Ilyas MF. Hubungan usia dan masa kerja dengan posisi pergelangan tangan terhadap carpal tunnel syndrome pada supir bajaj di Jakarta Barat. Jakarta: Universitas Muhammadiyah Jakarta, 2015.

9. Meagan S, Melissa B. Work related risk factors for carpal tunnel syndrome. Accident Compensation Coorporation. 2014 [disitasi 15 Juni 2019]. Tersedia dari: https://www.acc.co.nz/assets/research/05 944ee617/work-risk-carpal-tunnel.pdf

10. Bahruddin, Putra RL, Alief HF, dkk. Hubungan masa kerja dengan kejadian carpal tunnel syndrome pada pekerja pemetik daun teh. Malang: Fakultas Kedokteran Universitas Muhhamadiyah Malang, 2016.

11. Juniari GAR, Wahyudi AT. Hubungan antara masa kerja terhadap keluhan carpal tunnel syndrome pada pegawai perempuan di kampus Universitas Dhyana Pura yang bekerja menggunakan komputer. Jurnal Virgin 2015;1(2):162-8.

12. Setiawan $A D$, Winaya $N$, Muliarta. Hubungan posisi pergelangan tangan saat mengetik terhadap risiko terjadinya carpal tunnel syndrome (CTS) pada karyawan PT X. Denpasar: Fakultas Kedokteran Universitas Udayana, 2015.

13. Mallapiangi F, Wahyudi AA. Gambaran faktor pekerjaan dengan kejadian carpal tunnel syndrome (CTS) pada pengrajin batu tatakan di Desa Lempang Kec. Tanete Riaja Kabupaten Barru. Makassar: Al-Sihah-Public Health Science Journal. 2015;6(2):2.

14. Bickel KD. Carpal tunnel syndrome. JHS. 2010;35:147-52.

15. Aroori S, Spence RA. Carpal tunnel syndrome. Ulster Med J. 2008;77(1):6-17.

16. Arab AA, Elmaghrabi MM, Eltantawy $\mathrm{MH}$. Carpal tunnel syndrome: evaluation of its provocative clinical tests. Egyption Jurnal of Neurosurgery.2019;33(14):1-4

17. Atroshi I, Gummesson C, Johnsson R, Sprinchorn A. Symptoms, disability, and quality of life in patients with carpal tunnel syndrome.1999;24(2):388-404

18. Mondelli M, Giannini F, Giacchi M. Carpal tunnel syndrome incidence in a general population. Neurology. 2002;58:289-93 
19. Olney RK. Carpal tunnel syndrome: complex issues with a simple condition. Neurology. 2001;56:1431-2.

20. Foley M, Silverstein B, Polissar N. The economic burden of carpal tunnel syndrome: long term earnings of CTS claimant in Washington State. American Journal of Industrial Medicine. 2007;50:155-72. 